\title{
DILUTIONAL AND MODIFIED ULTRAFILTRATION REDUCES PULMONARY HYPERTENSION AFTER OPERATIONS FOR CONGENITAL HEART DISEASE: A PROSPECTIVE RANDOMIZED STUDY
}

Ko Bando, MD ${ }^{\mathrm{a}}$

Palaniswamy Vijay, $\mathrm{PhD}^{\mathrm{a}}$

Mark W. Turrentine, MD $^{\mathrm{a}}$

Thomas G. Sharp, MD ${ }^{\mathrm{a}}$

Lynda J. Means, MD ${ }^{\mathrm{b}}$

Gregory J. Ensing, $\mathrm{MD}^{\mathrm{c}}$

Brian J. Lalone, CCP ${ }^{\mathrm{a}}$

Yasuo Sekine, MD $^{\mathrm{a}}$

Laszlo Szekely, MD ${ }^{\mathrm{a}}$

John W. Brown, MD
Objective: A prospective randomized study was performed to test whether removal of endothelin-1, by ultrafiltration techniques, will reduce pulmonary hypertension after operations for congenital heart disease. Methods: Twentyfour patients with pulmonary hypertension (systolic pulmonary/systemic arterial pressure ratio $>60 \%$ ) undergoing cardiac operations were randomized into a control group $(n=12)$ having conventional ultrafiltration and an experimental group $(n=12)$ undergoing dilutional ultrafiltration during and modified ultrafiltration after cardiopulmonary bypass. Plasma endothelin-1, nitric oxide metabolites, and cyclic guanosine monophosphate were assayed before bypass, 10 minutes into bypass, after bypass, and 0, 3, 6, and 12 hours after the operation in both groups, as well as in the ultrafiltrates and after modified ultrafiltration in the experimental group. Both groups received $\alpha$-blockers (chlorpromazine and/or prazosin) postoperatively using the same guidelines. Results: The ultrafiltrates contained significant amounts of endothelin-1 $(1.81 \pm 0.86 \mathrm{pg} / \mathrm{ml}$, dilutional, and $6.44 \pm 1.82 \mathrm{pg} / \mathrm{ml}$, modified ultrafiltrate). Endothelin-1 and the pulmonary/systemic pressure ratio were significantly lower in experimental compared with control patients. Nitric oxide metabolites and cyclic guanosine monophosphate increased similarly in both groups for 12 hours after the operation $(p=$ not significant). Three of 12 control patients $(25 \%)$ but no experimental patients had pulmonary hypertensive crises $(p=0.07)$. The experimental patients required significantly less ventilatory support $(67 \pm 47$ hours vs $178 \pm 139$ hours for control patients, $p=$ 0.048). Conclusions: Dilutional and modified ultrafiltration reduce endothelin-1 and the pulmonary/systemic pressure ratio postoperatively and may become an important adjunct for preventing pulmonary hypertension after operations for congenital heart disease in high-risk patients. (J Thorac Cardiovasc Surg 1998; 115:517-27)

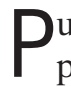
ulmonary hypertension associated with increased pulmonary vascular resistance is a significant cause of morbidity and mortality after the use of

From the Section of Cardiothoracic Surgery, ${ }^{\text {a }}$ Divisions of Pediatric Anesthesiology ${ }^{\mathrm{b}}$ and Pediatric Cardiology, ${ }^{\mathrm{c}}$ James W. Riley Hospital for Children and Indiana University Medical Center, Indianapolis, Ind.

Read at the Seventy-seventh Annual Meeting of The American Association for Thoracic Surgery, Washington, D.C., May 4-7, 1997.

Received for publication May 7, 1997; revisions requested June 10, 1997; revisions received Nov. 4, 1997; accepted for publication Nov. 4, 1997.

Address for reprints: Ko Bando, MD, Section of Cardiothoracic Surgery, Indiana University Medical Center, 545 Barnhill Dr., EM 215, Indianapolis, IN 46202-5123.

Copyright (C) 1998 by Mosby, Inc.

$0022-5223 / 98 \$ 5.00+0 \quad \mathbf{1 2 / 6 / 8 7 3 5 3}$ cardiopulmonary bypass (CPB) for repair of congenital heart defects. ${ }^{1,2}$ Although the precise mechanism of pulmonary hypertension after operation for congenital heart disease remains poorly defined, recent evidence suggests that pulmonary vascular tone is regulated by a complex interaction of vasoactive substances that are locally produced by the vascular endothelium. ${ }^{3,4}$

Endothelin-1 (ET-1) is a 21-amino acid polypeptide produced by vascular endothelial cells, the potent vasoactive properties of which have been implicated in the pathophysiology of pulmonary hypertensive disorders. ${ }^{5}$ In patients with congenital heart disease and pulmonary hypertension, plasma concentrations of ET-1 increased immediately after CPB and showed a significant correlation to the ratio of pulmonary/systemic arterial pressure. ${ }^{6,7}$ In 
Table I. Preoperative diagnosis

\begin{tabular}{lcc}
\hline & Control & DUF/MUF \\
\hline VSD + PH & 6 & 5 \\
CAVC & 3 & 4 \\
TGA + VSD & 2 & 2 \\
TAPVC & 1 & 1 \\
Total & 12 & 12 \\
\hline
\end{tabular}

$D U F$, Dilutional ultrafiltration; $M U F$, modified ultrafiltration; $V S D$, ventricular septel defect; $P H$, pulmonary hypotension; $C A V C$, complete atrioventricular canal; TGA, transposition of great arteries; TAPVC, total anomalous pulmonary venous connection.

addition, it has been shown in lambs with increased pulmonary flow that pretreatment with ET-1 receptor blockers eliminates the vasoconstrictive response to alveolar hypoxia. ${ }^{8}$ These results suggest that alterations in ET-1 induced during CPB may be responsible in part for the increased pulmonary vascular resistance and increased vascular reactivity noted in children immediately after cardiac operations.

Modified ultrafiltration is a technique that uses ultrafiltration of the patient and hemofiltration of the CPB circuit after separation from bypass to reverse hemodilution occurring during cardiac operations. ${ }^{9,10}$ In children undergoing CPB for repair of congenital heart defects, modified ultrafiltration has been shown to reduce total body water, increase mean arterial pressure, increase cardiac index, and decrease pulmonary vascular resistance. ${ }^{11,12}$ Moreover, recent studies have demonstrated that some low molecular weight inflammatory mediators can be removed by hemofiltration during $\mathrm{CPB} .{ }^{13,14}$

Because the molecular weight of ET-1 is small $(2.5 \mathrm{kD}){ }^{15}$ we hypothesized that ET-1 could be removed using ultrafiltration techniques. ${ }^{16} \mathrm{We}$ conducted this randomized clinical trial to test the hypothesis that removal of plasma ET-1 by ultrafiltration techniques will reduce pulmonary hypertension after operations for congenital heart disease in which CPB is used.

\section{Patients and methods}

Twenty-four children with congenital heart disease associated with preoperative pulmonary hypertension caused by high pulmonary flow who were undergoing operations with the use of CPB at Riley Hospital for Children between September and December 1996 were included in this study. The study protocol was approved by the Institutional Review Board of the Indiana University School of Medicine. Informed consent was obtained from the parents of each child.

Patient groups. Using a random number table, 24 patients were assigned to one of two groups as follows: control group $(n=12)$ using conventional ultrafiltration and experimental group $(n=12)$ using dilutional ultrafiltration (DUF) during CPB and modified ultrafiltration (MUF) after CPB (DUF/MUF group). The preoperative diagnoses and patient characteristics for each group are depicted in Tables I and II. No significant differences were observed between the groups with respect to patient diagnoses and demographics.

Preoperative evaluation. Preoperative evaluation was performed by cardiac catheterization in all patients with ventricular septal defects (VSD), complete atrioventricular canal (CAVC), and three patients with transposition and ventricular septal defect (TGA + VSD), and by echocardiography in patients with total anomalous pulmonary venous connection (TAPVC) and one patient with TGA + VSD. Preoperative pulmonary hypertension was defined as a systolic pulmonary/systemic arterial pressure ratio $(\mathrm{Pp} / \mathrm{Ps})>60 \%$ by catheterization. The three patients not catheterized (TAPVC in two, TGA + VSD in one) had systemic or supersystemic pulmonary arterial pressure as estimated by echocardiography.

Operative management. Operative management was standardized during the time frame of this study. Cannulation was accomplished by use of the ascending aorta for inflow and separate caval cannulas inserted through the right atrial appendage, superior vena cava, or both. CPB was instituted at a flow rate of $2.4 \mathrm{~L} \cdot \mathrm{min}^{-1} \cdot \mathrm{m}^{-2}$, and the perfusate was cooled to $20^{\circ}$ to $28^{\circ} \mathrm{C}$ in most cases. The pump prime consisted of an electrolyte solution (PlasmaLyte-A, Baxter Healthcare Corp.) 400 to $900 \mathrm{ml}$, sodium bicarbonate 20 to $30 \mathrm{mEq}$, albumin $25 \%(12.5 \mathrm{gm} / 250 \mathrm{ml}$ of prime, to a final concentration of 5\%) and washed packed red blood cells sufficient to maintain a hematocrit value of $14 \%$ to $18 \%$. Ascorbic acid, $1 \mathrm{gm} / 10 \mathrm{~kg}$, methylprednisolone sodium succinate (SoluMedrol) $30 \mathrm{mg} / \mathrm{kg}$, and cefuroxime sodium $12.5 \mathrm{mg} / \mathrm{kg}$ were added to the prime at the initiation of bypass. For patients with TAPVC requiring circulatory arrest, a single venous cannula was used and the repair was performed after the perfusate was cooled to $15^{\circ} \mathrm{C}$ and maintained for 15 minutes. The left side of the heart was vented with a catheter inserted through the apex of the left ventricle or the left atrial appendage. Cold crystalloid cardioplegic solution was injected at a total volume of $15 \mathrm{ml} / \mathrm{kg}$. Topical hypothermia was added. The infusion of cardioplegic solution was repeated at 20- to 25-minute intervals or sooner if electrical activity was noted.

Technique of conventional ultrafiltration. In the conventional ultrafiltration group, patients were treated with ultrafiltration during $\mathrm{CPB}$, which removed excess fluid when it was present $(n=8)$ and hemoconcentrated the patient's blood. The total amount of fluid filtered by conventional ultrafiltration was $20.6 \pm 8.2 \mathrm{ml} / \mathrm{kg}$. Post$\mathrm{CPB}$ processing of blood from the extracorporeal circuit by a centrifugal red cell salvage process was also used in these patients.

Techniques of dilutional ultrafiltration. The DUF/ MUF patients received an augmented form of ultrafiltration during $\mathrm{CPB}$. In this dilutional ultrafiltration method, the patient-CPB circuit is actively exchanged by (1) setting the circuit parameters to allow ultrafiltrate formation at a rate equivalent to the crystalloid cardioplegia volume plus 
40 to $70 \mathrm{ml} / \mathrm{kg}$ per hour and (2) adding small aliquots of diluent (PlasmaLyte $\mathrm{A}<20 \mathrm{ml} / \mathrm{kg}$ ) as necessary to maintain a safe blood level in the venous reservoir of the $\mathrm{CPB}$ circuit. The dilutional ultrafiltration was carried out semicontinuously throughout the CPB run but was interrupted during weaning from $\mathrm{CPB}$ while inotropic or vasoactive drugs were being administered. ${ }^{16}$

Techniques of modified ultrafiltration. A venovenous modified ultrafiltration method was used on all patients in the DUF/MUF group. In this method, the patient's inferior vena caval blood was drawn into the modified ultrafiltration circuit (Fig. 1) through the tip of a dual-lumen hemodialysis catheter. The inferior vena caval blood within the modified ultrafiltration circuit was both ultrafiltered with a hemoconcentrator (model HPH400, Minntech, Minneapolis, Minn.) and oxygen-supplemented with aliquots of oxygenated, warmed CPB circuit blood that had previously been translocated to a reservoir. Aliquots of this oxygenated blood were administered during modified ultrafiltration to maintain appropriate filling pressures as ultrafiltrate was being formed. After being oxygen-supplemented and ultrafiltered, the modified ultrafiltration circuit blood was returned to the patient's right atrium through the proximal side holes of the dual-lumen catheter. Modified ultrafiltration was terminated when the supplement reservoir bag was empty. The duration of modified ultrafiltration was not measured in this study, but in prior pilot study, modified ultrafiltration was completed in $12 \pm 3$ minutes. The total amount of fluid filtered by dilutional ultrafiltration and modified ultrafiltration was $45.8 \pm 17.5 \mathrm{ml} / \mathrm{kg}, 124.7 \pm 25.6 \mathrm{ml} / \mathrm{kg}$, respectively.

After modified ultrafiltration, the dual-lumen cannula was removed, protamine was administered, and the patients were transfused as required with the residual modified ultrafiltration circuit blood. Protamine reversal was completed after the modified ultrafiltration circuit blood transfusions.

Intraoperative postrepair evaluation and monitoring. As patients were being warmed and weaned from bypass, pulmonary arterial, left atrial, and right atrial oximetric catheters were inserted for intraoperative and postoperative hemodynamic monitoring. Intraoperative nitroglycerin at a dose of 0.5 to $10 \mu \mathrm{g} / \mathrm{kg}$ per minute and nitroprusside at a dose of $3 \mu \mathrm{g} / \mathrm{kg}$ per minute were given in the early postoperative period. These agents were administered through a right atrial or pulmonary arterial line and titrated to keep $\mathrm{Pp} / \mathrm{Ps}<40 \%$. If dopamine or dobutamine was required at a dose of $>5 \mu \mathrm{g} / \mathrm{kg}$ per minute, it was delivered through the left atrial line in an attempt to reduce the potential for inducing pulmonary vasoconstriction.

Prevention strategy for postoperative pulmonary hypertension. Postoperative pulmonary hypertensive events included pulmonary hypertensive crises and persistent pulmonary hypertension. A pulmonary hypertensive crisis was defined as a syndrome of hyperacute rise in the systolic pulmonary/systemic pressure ratio $(\mathrm{Pp} / \mathrm{Ps}>70 \%)$ accompanied by a profound reduction in cardiac output and fall in $\mathrm{Svo}_{2}$. Persistent pulmonary hypertension was defined as a postoperative $\mathrm{Pp} / \mathrm{Ps}>70 \%$ continuing for longer than 6 hours after repair. Patients in both groups
Table II. Patient demographics

\begin{tabular}{lccc}
\hline & Control & DUF/MUF & $p$ Value \\
\hline Gender (M/F) & $6 / 6$ & $6 / 6$ & \\
Age (days) & $223 \pm 151$ & $180 \pm 167$ & 0.33 \\
Weight (kg) & $7.4 \pm 4.8$ & $5.2 \pm 1.3$ & 0.16 \\
Preop Qp/Qs & $2.8 \pm 0.4$ & $3.1 \pm 0.5$ & 0.57 \\
CPB time (min) & $130 \pm 36$ & $143 \pm 50$ & 0.49 \\
Ao clamp time & $73 \pm 19$ & $78 \pm 35$ & 0.73 \\
$\quad$ (min) & & &
\end{tabular}

$D U F$, Dilutional ultrafiltration; $M U F$, modified ultrafiltration; $Q p / Q s$, ratio of pulmonary versus systemic flow; $C P B$, cardiopulmonary bypass; $A o$, aortic.

were paralyzed and mechanically ventilated for at least 6 hours. Moderate hyperventilation was used when the $\mathrm{Pp} / \mathrm{Ps}$ ratio exceeded $40 \%$.

Both groups received prophylactic $\alpha$-blockers (chlorpromazine and/or prazosin) after $\mathrm{CPB}$ on the basis of a routine clinical protocol. Intravenous administration of chlorpromazine was begun in the immediate postoperative period at a dose of $0.25 \mathrm{mg}$ with adjustments for its pulmonary vasodilatory ( $\alpha$-adrenergic blockade) and central nervous system sedative effects as needed to a maximum of $2 \mathrm{mg}$ every 4 hours. If pulmonary hypertension $(\mathrm{Pp} / \mathrm{Ps}>50 \%)$ persisted after administration of chlorpromazine, prazosin (another $\alpha$-blocker) was given orally or by nasogastric tube beginning with $0.125 \mathrm{mg}$ and titrating up to $2 \mathrm{mg}$ every 4 hours.

Strategy for extubation. The protocol for initial respiratory management consisted of mechanical ventilator support to maintain $\mathrm{PaO}_{2}>120 \mathrm{~mm} \mathrm{Hg}, \mathrm{Paco}_{2} \cong 30$ to 35 $\mathrm{mm} \mathrm{Hg}$, and $\mathrm{pH} \cong 7.45$ to 7.50 to achieve minimal physiologic response to stimulation. Once the child exhibited hemodynamic stability for 12 to 24 hours, mechanical ventilatory support and sedation were weaned. When the child demonstrated the ability to sustain adequate spontaneous respiratory effort and required minimal supplemental oxygen as reflected by normal arterial blood gases, the child was extubated.

Measurement of ET-1, nitric oxide metabolites, and cyclic guanosine monophosphate. A $4 \mathrm{ml}$ blood sample was collected from the radial artery in a Vacutainer device (Becton Dickinson Vacutainer Systems, Franklin Lakes, N.J.) containing $500 \mathrm{KU}$ aprotinin to measure plasma ET-1, nitric oxide (NO) metabolites, and cyclic guanosine monophosphate (cGMP) at seven time points: immediately before $\mathrm{CPB}, 10$ minutes into $\mathrm{CPB}$, immediately after $\mathrm{CPB}$, and $0,3,6$, and 12 hours after $\mathrm{CPB}$. The plasma was separated immediately by centrifugation and stored at $-70^{\circ} \mathrm{C}$ until ET-1, NO, and cGMP were assayed.

The ET-1 assay was based on a two-site immunoenzymometric "sandwich" method (Amersham Life Science, Arlington, Ill.). ET-1 extracted by solid phase column chromatography from plasma samples was incubated with an IgG anti-endothelin antibody overnight at $4^{\circ} \mathrm{C}$. ET- 1 bound to anti-endothelin antibody was detected using a horseradish peroxidase conjugated anti-ET-1 F ab' fragment and compared with standard samples of known amounts of synthetic ET-1. The color developed after the addition of substrate was measured at $450 \mathrm{~nm}$. A standard 


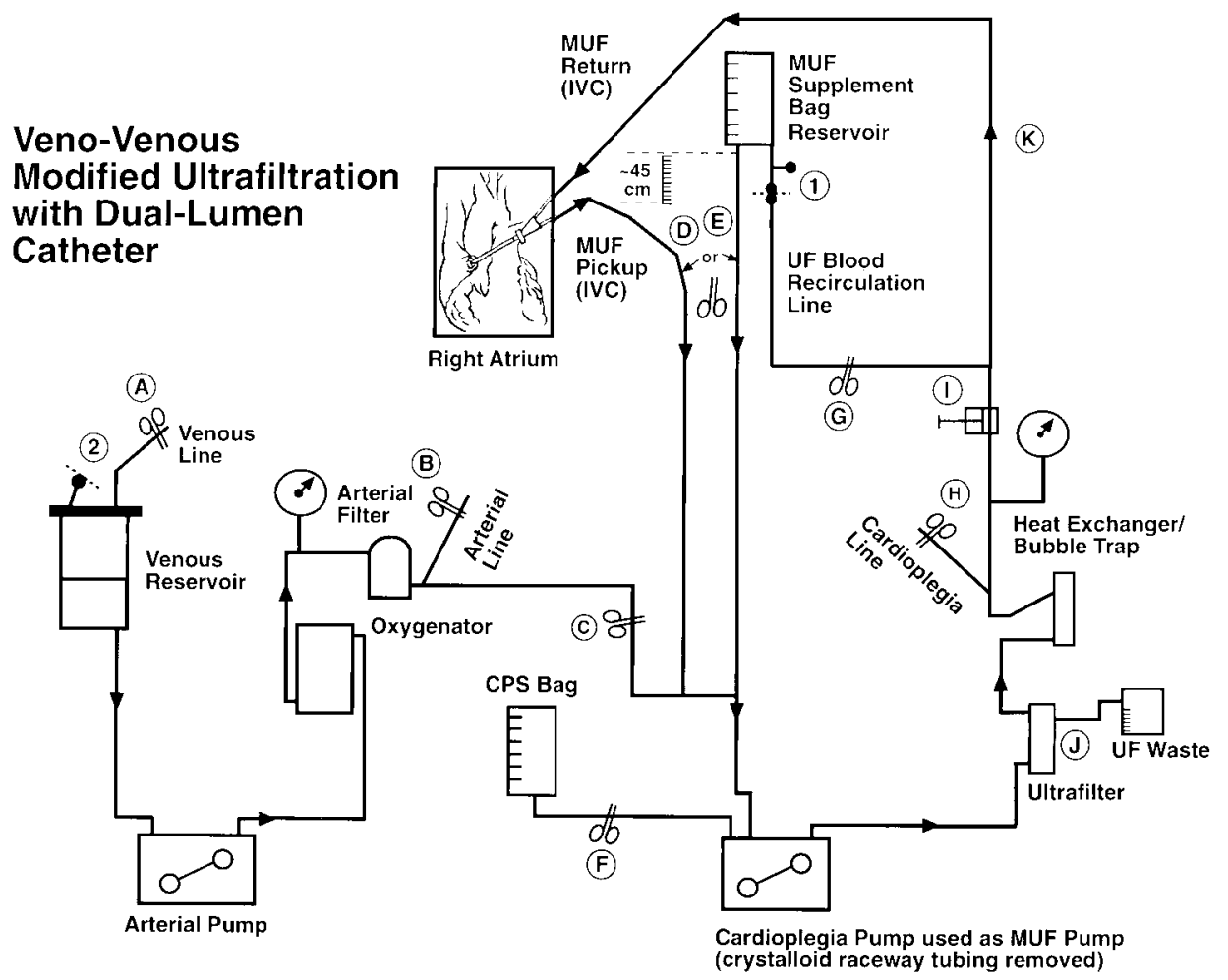

Fig. 1. Venovenous modified ultrafiltration circuit. In preparation for modified ultrafiltration, blood within the cardiopulmonary bypass circuit from the venous line through to the arterial filter was first crystalloid-chased to the modified ultrafiltration supplement bag reservoir. Modified ultrafiltration is next conducted during the post-cardiopulmonary bypass period by removing the tube clamps at circuit location $\mathrm{D}, \mathrm{J}$, and $\mathrm{K}$ and adjustment of microscrew clamp I to obtain an ultrafilter pressure of $400 \mathrm{~mm} \mathrm{Hg}$ while modified ultrafiltration pump flow rate is 10 to $30 \mathrm{ml} / \mathrm{kg}$ per minute. As ultrafiltered waste fluid is formed, the patient's central venous pressure is maintained by intermittently adding modified ultrafiltration supplement to blood by briefly moving the tubing clamp at location E to site D. Dilutional ultrafiltration is performed during cardiopulmonary bypass by placing the ultrafiltered blood recirculator line at stopcock position 2. Dotted lines indicate the modified ultrafiltration circuit. Letters within circles (A through $\mathrm{K}$ ) define potential positions(s) of tubing clamps for various uses of the circuit. Numbers within circles define alternate stopcock attachment points of the ultrafiltered blood recirculation line. CPS, Cardioplegic solution; $I V C$, inferior vena cava; $M U F$, modified ultrafiltration; $U F$, ultrafiltered.

curve was constructed and the amount of ET-1 present in the plasma was expressed as picograms per milliliter.

NO was measured using a commercially available kit (Boehringer Mannheim, Indianapolis, Ind.). Nitrate present in the sample was reduced to nitrite by reduced nicotinamide adenine dinucleotide phosphate and nitrate reductase. The red-violet diazo dye formed by the addition of sulfanilamide and $N$-1-naphthlyl-ethylenediamine dihydrochloride was measured at $550 \mathrm{~nm}$, and the concentration of NO metabolites was calculated from a calibration curve ranging from $0.8 \mu \mathrm{mol} / \mathrm{L}$ to $80 \mu \mathrm{mol} / \mathrm{L}$. $\mathrm{NO}$ values were expressed as micromoles per liter of NO metabolites.

The cGMP assay (Amersham Life Science, Arlington, Ill.) was based on competition between unlabeled cGMP and a fixed quantity of peroxidase-labeled cGMP in the presence of a limited amount of cGMP-specific antibody.
The concentration of cGMP in the sample was determined by interpolation of a standard curve ( 0 to 512 $\mathrm{pg} /$ well) and expressed as picograms per milliliter.

Because we intentionally diluted blood during $\mathrm{CPB}$ in the DUF/MUF group, the effect of hemodilution during $\mathrm{CPB}$ was not corrected for in this study.

Postoperative evaluation. A complete set of postoperative physiologic data was collected for all 24 patients, including arterial blood gas (oxygen tension, carbon dioxide tension, and $\mathrm{pH}$ ), requirement for inotropic support, cardiac rhythm, right atrial pressure, pulmonary arterial pressure, and systemic pressure. Postoperative hematocrit levels and requirements for red blood cells, platelets, and fresh frozen plasma were also collected. The duration of intubation and chest tube drainage were also monitored.

Statistical analysis. Data were analyzed with both the SAS (Statistical Analysis System, Inc., Cary, N.C.) and 
STATISTICA (Statsoft, Tulsa, Okla.) software packages. Differences in the levels of plasma ET-1, NO metabolites, cGMP, and the $\mathrm{Pp} / \mathrm{Ps}$ ratios between the groups were determined by ANOVA for repeated measures. The changes in ET-1, NO metabolites, cGMP, Pp/Ps within each group were compared between, before, and 12 hours after the operation by paired $t$ test. The incidence of postoperative pulmonary hypertensive crises and the requirement for $\alpha$-blocker prophylaxis and inotropic support were compared between the groups by Fisher's exact test. The duration of ventilatory support was compared between the groups using an unpaired $t$ test. All values were expressed as mean \pm standard deviation.

\section{Results}

Perioperative management, mortality, and incidence of postoperative pulmonary hypertension. No significant differences between the groups in CPB time or aortic crossclamp time were observed. The requirements for NO donors and inotropic support for each group were also similar between the groups. As evident in Appendix 1, the requirement for prazosin was similar between the groups. However, high doses of chlorpromazine $(>1.5 \mathrm{mg})$ were required in $25 \%(3 / 12)$ of patients in the control group but not in the DUF/MUF group. No mortality occurred among the patients in this study. Three of 12 patients in the control group (25\%) but none of DUF/MUF patients experienced postoperative pulmonary hypertensive crises $(p=0.22)$. None of the patients in this study had persistent pulmonary hypertension after operation.

Perioperative changes of ET-1. The dynamic changes of ET-1 levels before and during CPB, at the end of modified ultrafiltration (DUF/MUF group only), and up to 12 hours after operation are depicted in Fig. 2. Plasma ET-1 increased slightly during CPB in both groups. In the DUF/ MUF group, $6.44 \pm 1.82 \mathrm{pg} / \mathrm{ml}$ of ET-1 was removed during modified ultrafiltration after $\mathrm{CPB}$, whereas only $1.81 \pm 0.86 \mathrm{pg} / \mathrm{ml}$ of ET -1 was removed in the dilutional ultrafiltration filtrate during CPB. Subsequently, plasma ET-1 levels were significantly lower after modified ultrafiltration and remained low up to 12 hours after operation. In sharp contrast, ET-1 levels in the control group were substantially increased after $\mathrm{CPB}$ and remained significantly higher than in the DUF/MUF group throughout the study period.

Perioperative changes of $\mathbf{P p / P s}$. Preoperative $\mathrm{Pp} / \mathrm{Ps}$ were similar between the groups. However, at the end of the operations, $\mathrm{Pp} / \mathrm{Ps}$ in the control group were significantly higher compared with the DUF/

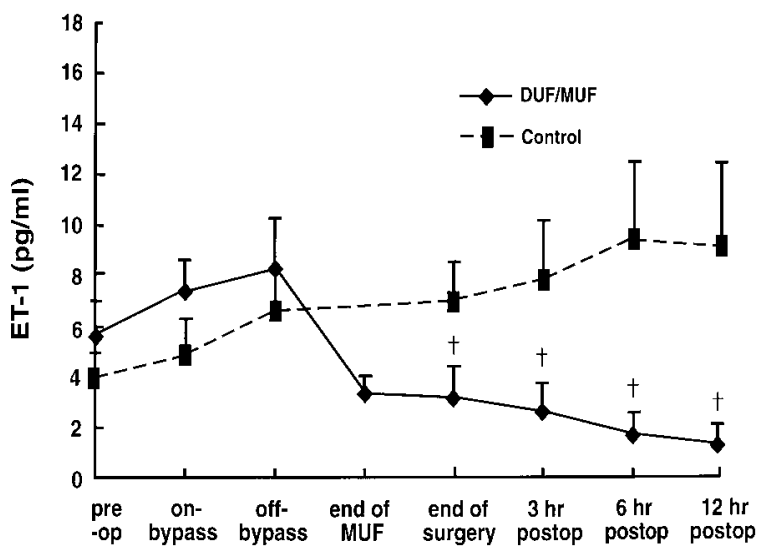

Fig. 2. Changes of arterial plasma endothelin-1 concentration at different times during perioperative period. $E T-1$, Endothelin-1; $D U F$, dilutional ultrafiltration; $M U F$, modified ultrafiltration. $\uparrow p<0.01$ versus control group.

MUF group, and this was maintained for up to 12 hours after operation (Fig. 3).

Perioperative changes in $\mathrm{NO}$ metabolites $\left(\mathrm{NO}_{2} /\right.$ $\mathrm{NO}_{3}$ ) and cGMP. NO production, as measured by the metabolites $\mathrm{NO}_{2} / \mathrm{NO}_{3}$, increased significantly in both groups during and after operation, and this persisted beyond 6 hours (Fig. $4, A$ ). The changes in cGMP were similar in both groups (Fig. $4, B$ ). No significant differences were observed between the groups with respect to either $\mathrm{NO}_{2} / \mathrm{NO}_{3}$ or cGMP throughout the study period.

Perioperative arterial blood gases and ventilator requirement after operation. Immediately after operation, oxygen tension $\left(\mathrm{Po}_{2}\right)$ in the DUF/MUF group $(430.0 \pm 91.0 \mathrm{~mm} \mathrm{Hg})$ was significantly higher than that of the control group $(282.0 \pm 66.5 \mathrm{~mm} \mathrm{Hg})$ $(p<0.05)$. The $\mathrm{pH}$ was maintained $>7.4$ in all patients after operation, and no significant differences in this parameter were observed between the groups during the first 12 hours after operation (Appendix 3). Patients treated with DUF/MUF required significantly shorter durations of ventilatory support ( $68 \pm 47$ hours) compared with control patients (178 \pm 139 hours) $(p=0.048)$.

Requirement for blood transfusion. The requirement for platelets and fresh frozen plasma through postoperative day 1 were significantly higher in control patients compared with DUF/MUF patients (Appendix 4).

\section{Discussion}

The mediators involved in the pulmonary hypertension after $\mathrm{CPB}$ in patients with congenital heart 


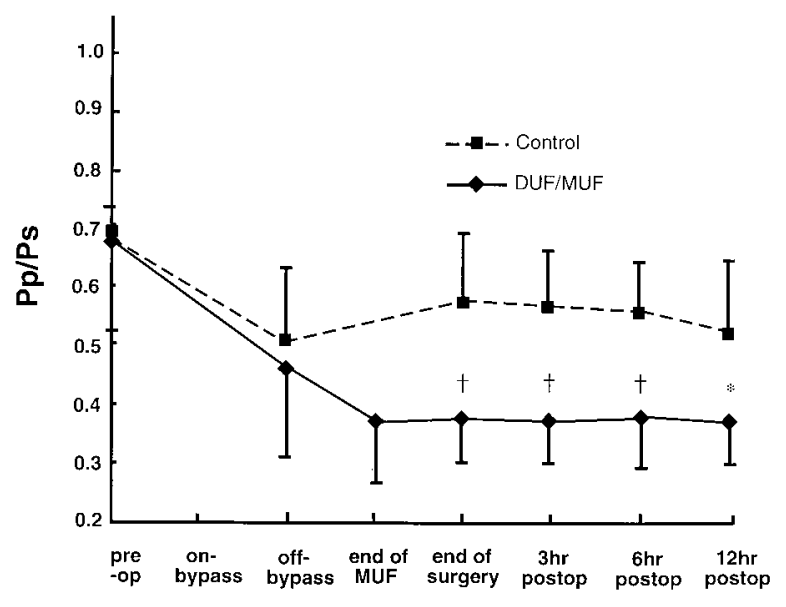

Fig. 3. Changes of $\mathrm{Pp} / \mathrm{Ps}$ at different times during the perioperative period. $P p / P s$, Systolic pulmonary/systemic arterial pressure ratio; $D U F$, dilutional ultrafiltration; MUF, modified ultrafiltration. ${ }^{*} p<0.05$ versus control group; $\uparrow p<0.01$ versus control group.

disease have been the focus of clinical and basic research for several years, and considerable progress has been made in identifying the mechanisms underlying this response. Pulmonary vascular tone is modulated by the vascular endothelium, which maintains a balance between vasodilators and vasoconstrictors. CPB alters the balance by impairing endothelium-dependent vasodilatation ${ }^{17,18}$ and increasing production of vasoconstrictors. ${ }^{19,}{ }^{20}$ Recent studies have shown that in patients with preoperative pulmonary hypertension, plasma ET-1 levels increase after $\mathrm{CPB}$, resulting in significant postoperative pulmonary hypertension. ${ }^{7,21}$

Because ET-1 increases significantly during and immediately after CPB, we tested whether the use of aggressive hemofiltration during and after CPB can successfully remove ET-1 and reduce pulmonary hypertension in high-risk patients with congenital heart disease.

This study demonstrates that combined dilutional and modified ultrafiltration efficiently removes free water $(170.0 \pm 43.1 \mathrm{ml} / \mathrm{kg})$ compared with conventional ultrafiltration $(20.6 \pm 8.2 \mathrm{ml} / \mathrm{kg})$. Consequently, this efficient ultrafiltration technique removed a significant amount of the circulating ET-1 $(1.81 \pm 0.86 \mathrm{pg} / \mathrm{ml}$ in the DUF ultrafiltrate, $6.44 \pm$ $1.82 \mathrm{pg} / \mathrm{ml}$ in the MUF filtrate) and maintained significantly lower plasma ET-1 levels compared with the control group. Subsequently, the Pp/Ps ratio in the DUF/MUF group was significantly lower compared with the control group for 12 hours after operation. As a result, 3 of 12 control patients (25\%), but none of the DUF/MUF patients had pulmonary hypertensive crises after CPB. Moreover, perhaps as a result of the reduced $\mathrm{Pp} / \mathrm{Ps}$ ratio, patients treated with DUF/MUF required significantly less ventilatory support.

This study cannot imply that ET-1 is the only source of postoperative pulmonary hypertension. Removal of free water and lower transfusion requirements may contribute to improved pulmonary mechanics after $\mathrm{CPB}^{22}$ and result in significantly lower postoperative $\mathrm{Pp} / \mathrm{Ps}$ and earlier extubation in the DUF/MUF patients. Removal of other cytokines, including tumor necrosis factor and interleukin- 6 and 8 , by ultrafiltration may also play a significant role in reducing postreperfusion lung injury. ${ }^{10,23}$

This study also does not indicate that DUF/MUF is a "magic bullet" for prevention of postoperative pulmonary hypertension. In our pilot study, a 6-month-old baby with CAVC associated with Down syndrome had a complete repair performed. Dilutional and modified ultrafiltration were used during and after CPB, and the $\mathrm{Pp} / \mathrm{Ps}$ was $30 \%$ on arrival in the intensive care unit. This child did not have $\alpha$-blocker prophylaxis, and 3 hours after intensive care unit admission, he had a pulmonary hypertensive crisis and required cardiopulmonary resuscitation and extracorporeal membrane oxygenation support for 5 days. We speculated that this may have been due to significant ET-1 production several hours after the cessation of bypass and modified ultrafiltration therapy. In addition, another vasoconstrictor such as thromboxane $\mathrm{B}_{2}$ might have played a significant role in the development of this pulmonary hypertensive event. Fortunately, this baby was successfully weaned from extracorporeal membrane oxygenation and survived. However, we learned a lesson from this experience that routine prophylaxis of postoperative pulmonary hypertension using $\alpha$-blockers, moderate hyperventilation, and sedation cannot be omitted.

The relative importance of dilutional ultrafiltration versus modified ultrafiltration remains unclear after this study. During CPB, ET-1 levels increased slightly in both groups and no significant differences were observed between groups. This implies that significant ET-1 is being produced during $\mathrm{CPB}$, and dilutional ultrafiltration may not be effective enough to remove the excess ET-1 because the total amount of ET-1 in the dilutional ultrafiltration filtrate $(1.81 \pm 0.86 \mathrm{pg} / \mathrm{ml})$ was significantly lower compared with that in the modified ultrafiltration filtrate 
$(6.40 \pm 1.82 \mathrm{pg} / \mathrm{ml})$. Recently, Journois and colleagues $^{24}$ studied the effect of combined use of arteriovenous modified ultrafiltration (after CPB) with a high-volume, zero-balance hemofiltration (during $\mathrm{CPB}$ ) and found improved outcomes in the combined group compared with modified ultrafiltration alone. In their study, zero-balance ultrafiltration was performed only during the rewarming phase of $\mathrm{CPB}$, whereas dilutional ultrafiltration was performed throughout CPB in our study. Moreover, the total amount of zero-balance ultrafiltrate was approximately three times the volume filtered by modified ultrafiltration in their study, whereas only one third of the amount of fluid filtered during modified ultrafiltration was removed by dilutional ultrafiltration in our study. Because the filtration techniques during $\mathrm{CPB}$ were widely different between these two studies, it is difficult to compare these findings. Nonetheless, we plan to perform a comparison of groups treated with dilutional ultrafiltration during CPB alone versus modified ultrafiltration after CPB. This future study might help determine whether dilutional ultrafiltration is necessary for effective removal of vasoactive mediators.

This prospective clinical study has several limitations. Radial artery samples were used to assess ET-1, NO metabolites, and cGMP. Thus the transpulmonary gradient of these mediators could not be assessed. However, in a sample of four patients, the concentration of ET-1 drawn simultaneously from the right and left atria and the pulmonary artery were similar in both control $(n=2)$ and the DUF/MUF patients (data not shown). This study and others demonstrated that plasma levels of ET-1 are elevated after CPB, and the ET-1 levels correlate well with the degree of pulmonary hypertension. ${ }^{6,8,21}$ However, because $90 \%$ of ET-1 is secreted by the vascular endothelium toward the vessel media, the significance of increased plasma levels can only be inferred. The local concentration of ET-1 may be more important than circulating levels in determining the response of a vascular bed. ${ }^{25}$ Further study, including measurement of ET-1 messenger RNA and ET-1 receptor expression in the pulmonary artery and lungs ${ }^{26}$ in animal models or patients with pulmonary hypertension will be necessary. ${ }^{7,8}$

In addition, other vasoactive mediators, including prostacyclin, thromboxane, and platelet-activating factor, were not measured because of the volume of blood required. The impact of residual intracardiac shunts, pulmonary stenosis, or both on postoperative
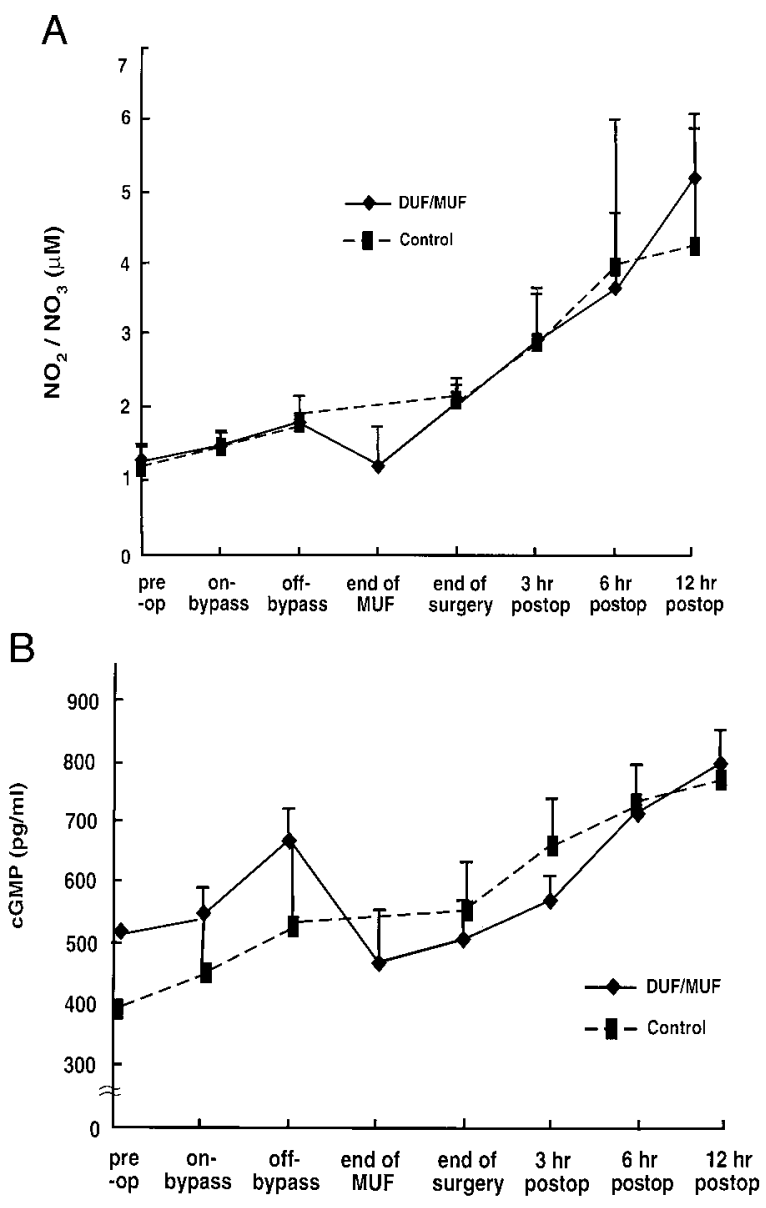

Fig. 4. A, Changes of plasma $\mathrm{NO}_{2} / \mathrm{NO}_{3}$ levels at different times during perioperative period. Postoperative plasma $\mathrm{NO}_{2} / \mathrm{NO}_{3}$ levels were significantly higher than preoperative levels and no significant differences were observed between two groups. B, Changes of plasma cyclic guanosine monophosphate levels at different times during perioperative period. Postoperative plasma $\mathrm{NO}_{2} / \mathrm{NO}_{3}$ levels were significantly higher than preoperative levels and no significant differences were observed between two groups. $c G M P$, Cyclic guanosine monophosphate; $D U F$, dilutional ultrafiltration; $M U F$, modified ultrafiltration.

pulmonary flow and pressure must also be considered. Two minimal residual shunts after CAVC repair and one mild pulmonary stenosis after TGA + VSD repair were detected by intraoperative echocardiography in this series. These were not considered to be physiologically significant, but their impact on vasoactive mediators could not be assessed.

Temperature and flow of CPB are important factors in determining the production of ET- 1 and other cytokines after CPB and subsequent development of pulmonary hypertension. ${ }^{11,27}$ In this ran- 
domized study, one patient with total anomalous pulmonary venous return in each group underwent repair with total circulatory arrest. The systemic temperature and $\mathrm{CPB}$ flow rates in the other patients were similar between the groups. Nonetheless, the impact of bypass temperature and flow on postoperative ET-1 production and pulmonary hypertension needs to be evaluated.

Another potentially confounding factor in this study is the use of inotropic agents postoperatively. This was not uniform for every patient, but conformed to general guidelines established by the attending physicians. Although administration of inotropic agents may have changed the balance of pulmonary vascular tone in some patients, this could not be independently analyzed because of the relatively small number of patients in each group. However, no differences were observed in the mean use of dopamine and dobutamine between the groups of patients (Appendix 1).

In conclusion, higher levels of ET-1 may predispose patients to pulmonary hypertension after operations for congenital heart defects. A combination of dilutional and modified ultrafiltration reduced plasma ET-1 and the pulmonary/systemic pressure ratio after $\mathrm{CPB}$ and resulted in lower ventilator requirements. Thus the use of aggressive ultrafiltration techniques during and after CPB may represent an important adjunct for the prevention of pulmonary hypertension early after operations for congenital heart disease in high-risk patients.

\section{REFERENCES}

1. Hopkins RA, Bull C, Haworth SG, de Leval MR, Stark J. Pulmonary hypertensive crises during cardiac surgery for congenital heart defects in young children. Eur J Cardiothorac Surg 1991;5:628-34.

2. Bando K, Turrentine MW, Sharp TG, Sekine Y, Aufuero TX, Sun K, et al. Pulmonary hypertension after operations for congenital heart disease: analysis of risk factors and management. J Thorac Cardiovasc Surg 1996;112:1600-9.

3. Vane JR, Anggard EE, Botting RM. Regulatory functions of the vascular endothelium. N Engl J Med 1990;323:27-36.

4. Cooper CJ, Landsberg MJ, Anderson TJ, Charbonneau F, Creager MA, Ganz P, et al. Role of nitric oxide in the local regulation of pulmonary vascular resistance in humans. Circulation 1996;93:266-71.

5. Yanagisawa M, Kurihara H, Kimura S, Tomobe Y, Kobayashi M, Mitsui Y, et al. A novel potent vasoconstrictor peptide produced by vascular endothelial cells. Nature 1988; 332:411-5.

6. Komai H, Adatia IT, Elliot MJ, de Leval MR, Haworth SG. Increased plasma levels of endothelin-1 after cardiopulmonary bypass in patients with pulmonary hypertension and congenital heart disease. J Thorac Cardiovasc Surg 1993;106: 473-8.
7. Bando K, Vijayaraghavan P, Turrentine MW, Sharp TG, Morelock RJ, Brown JW. Dynamic changes of endothelin-1, nitric oxide and cyclic GMP in patients with congenital heart disease. Circulation 1997;96(Suppl):II346-51.

8. Reddy VM, Hendricks-Munoz KD, Rajasinghe HA, Petrossian E, Hanley FL, Fineman JR. Post-cardiopulmonary bypass pulmonary hypertension in lambs with increased pulmonary blood flow: a role for endothelin-1. Circulation 1997;95: 1054-61.

9. Naik SK, Knight A, Elliott MJ. A successful modification of ultrafiltration for cardiopulmonary bypass in children. Perfusion 1991;6:41-50.

10. Elliott MJ. Ultrafiltration and modified ultrafiltration in pediatric open heart operations. Ann Thorac Surg 1993;56:1518-22.

11. Naik SK, Knight A, Elliott M. A prospective randomized study of a modified technique of ultrafiltration during pediatric openheart surgery. Circulation 1991;84(Suppl):III422-31.

12. Naik SK, Elliott MJ. Ultrafiltration and pediatric cardiopulmonary bypass. Perfusion 1993;8:101-12.

13. Anderson S, Gothberg S, Berggren H, Bengtsoon A, Eriksson E, Risburg B. Hemofiltration modifies complement activation after extracorporeal circulation in infants. Ann Thorac Surg 1993;56:1515-7.

14. Millar AB, Armstrong L, van der Linden J, et al. Cytokine production and hemofiltration in children undergoing cardiopulmonary bypass. Ann Thorac Surg 1993;56:1499-502.

15. Goto K, Hama H, Kasuya Y. Molecular pharmacology and pathophysiological significance of endothelin. Jpn J Pharmacol 1996;72:261-90.

16. LaLone BJ, Frederick CC, Horner MT, Richmond LH, Bezruczko AP, Morris SM, et al. Modified ultrafiltration after congenital heart surgery: a venovenous method using a dual lumen hemodialysis catheter [abstract]. AmSECT Today 1997;3:29.

17. Wessel DL, Adatia I, Giglia TM, Thompson JE, Kulik TJ. Use of inhaled nitric oxide and acetylcholine in the evaluation of pulmonary hypertension and endothelial function after cardiopulmonary bypass. Circulation 1993;88(pt 1): 2128-38.

18. Kirshbom PM, Jacobs MT, Tsui SS, et al. Effects of cardiopulmonary bypass and circulatory arrest on endothelium dependent vasodilation in the lung. J Thorac Cardiovasc Surg 1996;111:1248-56.

19. Shafique T, Johnson RG, Dai HB, Weintraub RM, Johnson RG. Cardiopulmonary bypass and pulmonary thromboxane generation. Ann Thorac Surg 1993;55:724-8.

20. Cave AC, Manche A, Derias NW, Hearse DJ. Thromboxane $\mathrm{A}_{2}$ mediates pulmonary hypertension after cardiopulmonary bypass in the rabbit. J Thorac Cardiovasc Surg 1993;106:959-67.

21. Hiramatsu T, Imai Y, Takanashi Y, et al. Time course of endothelin-1 and nitrate anion levels after cardiopulmonary bypass in congenital heart defects. Ann Thorac Surg 1997;63: 648-52.

22. Meliones JN, Gaynor JW, Wilson BG, et al. Modified ultrafiltration reduces airway pressures and improves lung compliance after congenital heart surgery. J Am Coll Cardiol 1995;27:1A.

23. Journois D, Pouard P, Greeley WJ, Mauriat P, Vouhe P, Safran D. Hemofiltration during cardiopulmonary bypass in pediatric cardiac surgery: effects on hemostasis, cytokines, and complement components. Anesthesiology 1994;81: 1181-9. 
24. Journois D, Israel-Biet D, Pouard P, et al. High-volume, zero-balanced hemofiltration to reduce delayed inflammatory response to cardiopulmonary bypass in children. Anesthesiology 1996;86:965-76.

25. Rubanyi GM, Polokoff MA. Endothelins: molecular biology, biochemistry, pharmacology, and pathophysiology. Pharmacol Rev 1994;46:338-44.

26. Kirshbom PA, Page SO, Jacobs MT, et al. Cardiopulmonary bypass and circulatory arrest increase endothelin- 1 production and receptor expression in the lung. J Thorac Cardiovasc Surg 1997;113:777-83.

27. Skaryak LA, Kirshbom PM, DiBernardo LR, et al. Modified ultrafiltration improves cerebral metabolic recovery after circulatory arrest. J Thorac Cardiovasc Surg 1995;109:744-52.

\section{Discussion}

Dr. Ross M. Ungerleider (Durham, N.C.). When our group first began using ultrafiltration several years ago, there were very little data to justify its widespread use, and the technique did not gain general acceptance for several years. It has now been demonstrated from a variety of laboratory and clinical studies, some by us and many by others, that modified ultrafiltration acutely improves cardiac and pulmonary function after bypass and quite possibly cerebral recovery in patients exposed to periods of deep hypothermic circulatory arrest. Furthermore, it has been suggested that these improvements are related to the proven ability of modified ultrafiltration to remove excess water and low molecular weight mediators from the patient. It is now becoming more commonplace to find groups using ultrafiltration, at least in the neonatal and infant population, and many groups who use variations of the technique are impressed that it is indeed doing something beneficial for their patients compared with when ultrafiltration is not used.

In your study you compared conventional ultrafiltration with a technique that combined filtration on bypass and filtration after bypass. It is not clear how much actual filtration was accomplished in your control group because you state that filtration was performed only when fluid was available. Therefore it seems that you are basically comparing a group with no effective filtration to a second group exposed to two kinds of effective filtration. What was the average amount of fluid filtered for the control group? Did you measure the endothelin-1 in the filtrate obtained by each separate method?

Some surgeons are reluctant to use post-bypass filtration for fear of creating patient instability. In a future study, as you mentioned, could you compare your onbypass dilutional filtration, which at least appears to be a somewhat effective and consistent modality for on-bypass filtration in your hands, to postbypass modified ultrafiltration? Why did you design your study so that you combine the impact of dilutional and modified ultrafiltration? It might be that they will provide equivalent clinical advantage, especially with respect to the parameters that you followed in these patients. Because of your study design, you really have not answered whether post-bypass filtration is superior to effective on-bypass filtration, at least with respect to postoperative pulmonary hypertension and circulating endothelin-1 levels.

The other aspect of your study that is worthy of comment is the nature of endothelin-1, which acts on vascular smooth muscle. You address this in your discussion, but it is important to emphasize. Because circulating endothelin-1 probably does not affect vascular smooth muscle, how can we know that what you are measuring reflects a comparable increase or decrease in endothelin-1 effect on the pulmonary vascular smooth muscle? Your graph, for example, displays pulmonary/systemic pressure ratios. What are the actual pulmonary artery pressures and systemic pressures? Could your difference reflect the improvement in systemic artery pressure, which is well known after modified ultrafiltration because this will lower the pulmonary/systemic ratios irrespective of the endothelin-1 levels? Your conclusions are convincing, but please comment on how cautious we should be in interpreting these data.

Finally, it is important to realize that as effective as ultrafiltration appears to be in your patients, it is being applied after the injury has occurred. It seems to be effective at reducing the clinical impact of bypass-induced injury, but could you speculate for a moment about the injury itself? Could you recognize any factors that seem to relate to a greater likelihood of post-bypass pulmonary hypertension? Although your group seems to be well controlled, the preoperative $\mathrm{Po}_{2}$ in the control group is lower. Our laboratory has found that preoperative hypoxia may relate to lung injury. Did all groups have so-called total bypass? We found, and will be presenting elsewhere, information that suggests that a lack of flow to the pulmonary arteries during bypass increases postbypass lung injury. Observations by astute clinicians can be helpful. Do you have any sense despite the clinical sameness of your groups for factors that might make patients most susceptible to bypass-related pulmonary injury?

Dr. Bando. Thank you very much, Dr. Ungerleider.

Your first question is related to why we use conventional ultrafiltration in the controls. I totally agree with you that conventional ultrafiltration is not effective enough because a mean of $20 \mathrm{ml} / \mathrm{kg}$ of fluid was filtered during conventional ultrafiltration, which is about half of the amount of fluid filtered by dilutional ultrafiltration. However, dilutional and modified ultrafiltration are relatively new, and for those surgeons who do not use modified ultrafiltration or dilutional ultrafiltration, conventional ultrafiltration is the standard technique. Thus we believe it is appropriate to use the conventional ultrafiltration group as conventional treatment control patients. Unlike other institutions, we use venovenous ultrafiltration instead of arteriovenous ultrafiltration. By use of this technique, it is easy to maintain the desired filling pressure, and we were able to avoid the significant arteriovenous shunts during modified ultrafiltration. So the fear of creating patient hemodynamic instability has been eliminated.

Regarding the effect of dilutional versus modified ultrafiltration, that is a valid question. Because the total amount of endothelin-1 in the dilutional ultrafiltrate is so small, we may be able to delete the dilutional ultrafiltration part. However, a possibility also exists that other mediators that may act as a stimulator for endothelin-1 production are filtered out using dilutional ultrafiltration. 
Thus, as you mentioned, it is important to compare these two different techniques.

In terms of the significance of plasma endothelin-1, you are absolutely right. As your laboratory recently demonstrated in the total circulatory arrest model, it is important to measure the ET-1 mRNA or ET-1 receptors in the lung. However, this is only practical in an animal experiment, and we were not able to do that in a clinical randomized study like this. I would like to mention, however, that previous studies, including ours, one from Tokyo Women's Medical College, and one from Great Ormond Street Hospital in London, clearly demonstrated that a significant correlation exists between the plasma ET-1 level and pulmonary hypertension.

Regarding the question of pulmonary/systemic arterial pressure ratio versus actual pulmonary or systemic pressure (Appendix 2), we use the $\mathrm{Pp} / \mathrm{Ps}$ for the following reasons: First, this study includes a relatively wide range of age of the patients from neonates up to $2 \frac{1}{2}$ years old; thus the normal arterial pressure may be different among the patients. Second, as you pointed out, we did see the increase in systemic pressure after modified ultrafiltration, about 10 to $15 \mathrm{~mm} \mathrm{Hg}$, but this persisted only an hour or so. Third, we defined preoperative pulmonary hypertension as pulmonary/systemic arterial pressure ratio greater than $60 \%$. For these reasons, I believe it is still fair to document the $\mathrm{Pp} / \mathrm{Ps}$ ratios and compare these parameters between the groups. Another way to look at this problem is to express the change of postoperative pulmonary arterial pressure as the percent change of baseline or preoperative pulmonary arterial pressure. That might help to answer your question.
You also asked about the timing of injury. The previous studies show that the ET-1 level was high with patients with high flow and high pulmonary arterial pressure preoperatively. Thus pulmonary endothelial function has been already impaired and $\mathrm{CPB}$ merely exaggerates this injury. So it might be interesting to see the effect of an ET-1 receptor antagonist administered before $\mathrm{CPB}$ versus after CPB and compare the results.

Regarding the question of bypass technique, except for one patient in each group with circulatory arrest, we used the bicaval cannulation and the total CPB. As you mentioned, the preoperative $\mathrm{Po}_{2}$ in the control group is somewhat lower compared with experimental groups, but this is not statistically significant. I cannot make further comment on this because the sample size in each group was relatively small.

Your final question is related to the clinical impression of which subgroup of the patients might be more vulnerable to postoperative pulmonary hypertension. I can only say that you cannot rely on the $\mathrm{Pp} / \mathrm{Ps}$ ratio immediately after modified ultrafiltration to predict the degree of postoperative pulmonary hypertension. We had one patient with complete atrioventricular canal and Down syndrome in our preliminary study who had a $\mathrm{Pp} / \mathrm{Ps}$ of $30 \%$ after modified ultrafiltration, and we eliminated the $\alpha$-blocker prophylaxis and tried to extubate early. The patient had a severe pulmonary hypertensive crisis after 3 hours of admission to the intensive care unit and ended up with extracorporeal membrane oxygenation support for 5 days. We were able to save this patient, but I must say that this modified ultrafiltration is a valuable adjunct but not a magic bullet.

Appendix 1. The use of inotropic agents and $\alpha$-blocker

\begin{tabular}{|c|c|c|c|c|}
\hline & & & $\begin{array}{l}\text { Control } \\
(n=12)\end{array}$ & $\begin{array}{c}D U F / M U F \\
(n=12)\end{array}$ \\
\hline \multirow[t]{2}{*}{$\mathrm{CP}$} & $(\mathrm{mg})$ & mean (range) & $0.53(0.25-2)$ & $0.41(0.25-1.25)$ \\
\hline & & $\%($ No. Pt) & $100 \%(12 / 12)$ & $100 \%(12 / 12)$ \\
\hline \multirow[t]{2}{*}{ PR } & (mg) & mean (range) & $0.33(0.125-1.0)$ & $0.15(0.125)$ \\
\hline & & $\%($ No. $\mathrm{Pt})$ & $25 \%(3 / 12)$ & $8.3 \%^{\prime}(1 / 12)$ \\
\hline \multirow[t]{2}{*}{ NTG } & $(\mu \mathrm{g} / \mathrm{kg} / \mathrm{min})$ & mean (range) & $1.5(0.2-10)$ & $0.8(0.25-2)$ \\
\hline & & $\%$ (No. Pt) & $83 \%(10 / 12)$ & $50 \%(6 / 12)$ \\
\hline \multirow[t]{2}{*}{ NIP } & $(\mu \mathrm{g} / \mathrm{kg} / \mathrm{min})$ & mean (range) & $3.0(3.0)$ & $0(0)$ \\
\hline & & $\%($ No. Pt $)$ & $8.3 \%(1 / 12)$ & $(0 / 12)$ \\
\hline \multirow[t]{2}{*}{ Dop } & $(\mu \mathrm{g} / \mathrm{kg} / \mathrm{min})$ & mean (range) & $4.5(3.0-10.0)$ & $5.2(3.0-10)$ \\
\hline & & $\%($ No. Pt) & $42 \%(5 / 12)$ & $50 \%(6 / 12)$ \\
\hline \multirow[t]{2}{*}{ Dob } & $(\mu \mathrm{g} / \mathrm{kg} / \mathrm{min})$ & mean (range) & $4.0(3.0-7.0)$ & $3.7(2.5-5.0)$ \\
\hline & & $\%($ No. Pt) & $33 \%(4 / 12)$ & $25 \%(3 / 12)$ \\
\hline
\end{tabular}

DUF, Dilutional ultrafiltration; $M U F$, modified ultrafiltration; $C P$, chlorpromazine; $P R$, prazosin, $N T G$, nitroglycerin; Nip, nitroprusside; $D o p$, dopamine, $D o b$, dobutamine. 
Appendix 2. Changes in actual pulmonary arterial pressure and systemic pressure before, during, and after surgery

\begin{tabular}{|c|c|c|c|c|c|c|c|c|}
\hline & & Preoperative & Off-bypass & End of $M U F$ & End of surgery & $\begin{array}{c}3 \mathrm{hr} \\
\text { Postoperative }\end{array}$ & $\begin{array}{c}6 \mathrm{hr} \\
\text { Postoperative }\end{array}$ & $\begin{array}{c}12 \mathrm{hr} \\
\text { Postoperative }\end{array}$ \\
\hline \multirow[t]{2}{*}{ Pp } & $\begin{array}{l}\text { Control } \\
(\mathrm{mm} \mathrm{Hg})\end{array}$ & $53.3 \pm 15.3$ & $36.0 \pm 13.4$ & - & $41.5 \pm 5.7$ & $43.5 \pm 9.9$ & $40.2 \pm 7.7$ & $36.5 \pm 7.4$ \\
\hline & $\begin{array}{l}\text { DUF/MUF } \\
(\mathrm{mm} \mathrm{Hg})\end{array}$ & $46.9 \pm 10.8$ & $29.4 \pm 11.5$ & $28.9 \pm 8.1$ & $31.8 \pm 8.7$ & $32.4 \pm 9.8$ & $31.9 \pm 9.3$ & $30.5 \pm 6.5$ \\
\hline \multirow[t]{2}{*}{ Ps } & $\begin{array}{l}\text { Control } \\
(\mathrm{mm} \mathrm{Hg})\end{array}$ & $81.7 \pm 26.2$ & $73.2 \pm 16.8$ & - & $74.2 \pm 13.2$ & $81.5 \pm 14.0$ & $76.8 \pm 10.4$ & $77.3 \pm 14.2$ \\
\hline & $\begin{array}{l}\text { DUF/MUF } \\
(\mathrm{mm} \mathrm{Hg})\end{array}$ & $72.7 \pm 14.9$ & $69.8 \pm 17.6$ & $83.9 \pm 11.5$ & $84.3 \pm 16.2$ & $83.6 \pm 11.3$ & $83.9 \pm 14.6$ & $83.5 \pm 14.9$ \\
\hline
\end{tabular}

$P p$, Systolic pulmonary pressure; $P s$, systemic pressure; $D U F$, dilutional ultrafiltration; $M U F$, modified ultrafiltration.

Appendix 3. Preoperative and postoperative arterial blood gas

\begin{tabular}{|c|c|c|c|c|c|c|}
\hline & \multicolumn{2}{|c|}{ Preoperative } & \multicolumn{2}{|c|}{ End of operation } & \multicolumn{2}{|c|}{$3 \mathrm{hr}$ after operation } \\
\hline & Control & $D U F / M U F$ & Control & $D U F / M U F$ & Control & $D U F / M U F$ \\
\hline $\mathrm{pH}$ & $7.43 \pm 0.04$ & $7.44 \pm 0.10$ & $7.52 \pm 0.02$ & $7.46 \pm 0.07$ & $7.44 \pm 0.07$ & $7.47 \pm 0.06$ \\
\hline $\mathrm{PCO}_{2}(\mathrm{~mm} \mathrm{Hg})$ & $39.0 \pm 3.0$ & $36.0 \pm 4.2$ & $27.0 \pm 4.0$ & $32.4 \pm 4.5$ & $38.0 \pm 8.3$ & $32.9 \pm 3.3$ \\
\hline $\mathrm{PO}_{2}(\mathrm{~mm} \mathrm{Hg})$ & $175.0 \pm 97.5$ & $341.0 \pm 163.0$ & $282.0 \pm 66.5$ & $430.0 \pm 91.0^{*}$ & $184.7 \pm 49.3$ & $168.9 \pm 81.7$ \\
\hline $\mathrm{SaO}_{2}(\%)$ & $98.0 \pm 2.0$ & $98.6 \pm 2.8$ & $99.5 \pm 0.5$ & $100.0 \pm 0$ & $98.0 \pm 2.9$ & $95.9 \pm 8.5$ \\
\hline \multirow[t]{8}{*}{$\mathrm{FiO}_{2}(\%)$; mean (range) } & $75(21-100)$ & $74(21-100)$ & $100(100)$ & $100(100)$ & $80(50-100)$ & $44(35-60)$ \\
\hline & \multicolumn{2}{|c|}{6 hr after operation } & & & \multicolumn{2}{|c|}{$12 \mathrm{hr}$ after operation } \\
\hline & Control & $D U F / M U F$ & & & Control & $D U F / M U F$ \\
\hline & $7.46 \pm 0$ & $7.46 \pm 0.05$ & & & $7.51 \pm 0.07$ & $7.45 \pm 0.08$ \\
\hline & $34.4 \pm 8.6$ & $35.1 \pm 6.3$ & & & $29.0 \pm 5.1$ & $33.6 \pm 5.1$ \\
\hline & $122.7 \pm 33.0$ & $134.2 \pm 65$ & & & $212.6 \pm 62.3$ & $198.3 \pm 71.6$ \\
\hline & $98.3 \pm 1.2$ & $95.9 \pm 2.3$ & & & $99.5 \pm 0.5$ & $100.0 \pm 0$ \\
\hline & $68(40-100)$ & $41(25-50)$ & & & $66(40-100)$ & $46(36-60)$ \\
\hline
\end{tabular}

DUF, Dilutional ultrafiltration; $M U F$, modified ultrafiltration.

${ }^{*} p<0.005$ vs control.

Appendix 4. Requirement of RBC, platelets, FFP

\begin{tabular}{llcc}
\hline & $\begin{array}{c}\text { Control } \\
(\mathrm{ml} / \mathrm{kg})\end{array}$ & $\begin{array}{c}\text { DUF/MUF } \\
(\mathrm{ml} / \mathrm{kg})\end{array}$ & p Value \\
\hline RBC & $83.02 \pm 30.89$ & $67.60 \pm 24.77$ & 0.42 \\
Platelet & $15.29 \pm 5.95$ & $6.78 \pm 3.18$ & 0.04 \\
FFP & $14.39 \pm 5.63$ & $6.36 \pm 3.16$ & 0.04 \\
\hline
\end{tabular}

$D U F$, Dilutional ultrafiltration; $M U F$, modified ultrafiltration; $R B C$, red blood cell; FFP, fresh frozen plasma. 